\title{
Employees Assistance Programme; Social Work at Workplace : An Evidence Based Review
}

\section{Kuntak Ghosh}

MSW, Ph.D. (Social Work), Social Work Practitioner and Researcher, Berhampore, Murshidabad, West Bengal, India

Corresponding author: kuntakghosh@gmail.com

Received: 11-09-2020

Revised: $13-11-2020$

Accepted: 03-12-2020

\begin{abstract}
Employees are the most precious and important resource of an organization. The goal of Employees Assistance Programme is to identify the problem of employees and help the employees to solve their problems either directly or through referral process. Hence EAP can be considered indispensable for organizational sustainability. During 1940 the concept of Employee's Assistance in Industries was emerged with a vision of treating the problems of alcoholism among employees. Afterwards the other psychosocial problems of employees such as family problems, mental health problems, substance abuse, marital problems, parenting problems, emotional problems have been incorporated in EAP. At present in India and worldwide EAP becomes inevitable process to deal with such problems of employees including issues of protecting human right, prevention of workplace discrimination and exploitations. Evidence says that social work tools like counselling, home visits, solution focused brief therapy, strength perspective, crisis intervention, feminist perspective, social group work, social case work and community organization methods are being used to ensure effective results in EAP which proves the significance of Social Work intervention in ensuring successful EAP in industries.
\end{abstract}

Keywords: Employees Assistance Programme, Social Work, organizational sustainability, mental health, substance abuse, marital problems, parenting problems, workplace discrimination and exploitations, counselling, solution focused brief therapy, strength perspective, crisis intervention

Industries are made up of people and function through people. This is the most precious and important resource. All other resources such as material, machines, capitals (Money) are collected, co-ordinated, utilized and sustained by people. Improper utilization and management of people of an industry or organization therefore leads to poor utilization of other resources and low productivity. For effective management and utilization of employees one must not forget that people are psycho-social beings with feelings, thoughts, emotion, desires, value systems and limitations and each and every human being is unique in terms of all the aforesaid qualities. Therefore mechanical and violent use of employees may bring disaster to an organizational set up. Simplicity in terms of interpersonal communications and relationships in between employees and administration, opportunities for personal growth of the employees in terms of standard of living and intellectual and moral development and measuring the success of an organization in terms of human scale i.e. personal, professional, moral, spiritual, socio-economic and socio-political growth of the individuals within the

How to cite this article: Ghosh, K. (2020). Employees Assistance Programme Social Work at Workplace : An Evidence Based Review. Int. J. Soc. Sci., 9(04): 301-306.

Source of Support: None; Conflict of Interest: None 
organization may therefore lead to ultimate success and productivity of the organization (Lal 2005). The goal of Employees Assistance Programme is to identify the problem, resolve the issue,help the employees to solve their problems or provide the employees with referrals and other resources to address the problem (Mbuyisa 2019). EAP is an organizational resource that utilizes specific core technologies to enhance employees' and workplaces' effectiveness through prevention, identification and resolution of personal and productive issues (Jacobson \& Lamb 2008). EAP is a programme to assist employees of a workspace towards prevention and solving personal problems including health, family and marital problems, alcoholism, drug addiction, legal, emotional, socio-economical, stress and all other personal issues that may affect their productivity [Employee Assistance Professionals' Association (EAPA) 2003]. According to PPC International (PPC Clinical Practice, 2004 cited by Mbuyisa 2019), EPA is a management tool arranged by the employer with the expectation that the utilization of the programme will decrease absenteeism, accidents, tardiness and mistakes and will increase employees' productivity. According to Employee Assistance Society of North America (EASNA), EPA is an employer-sponsored service, designed for helping the employees to deal with their personal or family problems, including mental health problems, substance abuse, various addictions, marital problems, parenting problems, emotional problems, and financial or legal concerns so that the employees may overcome the issues and retain with the job with effectiveness. If the employees of an organization continue to suffer from psycho-social and personal problems in workplace or personal set ups it becomes very hard for the organization to grow and achieve sustainability. Hence the employer should sponsor and patronize effective EAP measures as an indispensable part of their HRM strategies for assisting the employees to solve their problems, achieve their objective and contribute maximum to the productivity and sustainability of the organization. Zastraw (2010) pointed out that the main duties of Social Work in industries are - to help the workers to adapt with the living and working conditions, to help them to meet their personal needs and to deal with family and personal problems of the workers for ensuring work-life balance. Social Work practice is framed by ideologies that attend to issue of person-in-environment fit, psychological well-being and need for social institutions to be responsive to economic, health and safety concerns of individuals, groups and communities (Tangeberg \& Kemp 2002,p 9). These concepts clearly indicate that EAP is the growing practice area for Social Work practitioners in Workplace set ups. The Social Workers with their multispectral knowledge and skills can extend their support to the employees to reduce their stress and develop their coping abilities; overcome the problems of substance abuse, domestic violence, mental health problems, socio-economic and other personal issues (Sharma \& Mishra 2017), which can affect their productivity and organizational sustainability.

Occupational Social Work in EAP: The Historical Background: The Concept of Employees Assistance was emerged in 1940 to address the issue of alcoholism and its effect on workplace. That time the programme used to be called as Occupational Alcohol Programmes (OAP). The OAP programme then came up with moderate success in supporting the employees to recover from the problem and get back to their work. DuPont de Nemours Company and Kodak Park of Eastern Kodak Company was the first two major corporate to adapt the OAP programme. Through amendment of Hughes Act 1970 the USA Government promoted the OAP to get practiced in Government agencies and Military Installations. In 1972 the provision of Drug Abuse was also incorporated in the Act (Jacobson \& Lamb 2008). While legislations started promoting the OAP the requirement for vast area of intervention for employee's assistance in organizations was felt for development of worker's productivity and organizational sustainability. As a result multidimensional problems of employees like family and marital problems, legal issues, health problems, mental health issues, socio economic problems and other social challenges of the employees were started to be addressed under OAP and then the expansion of services under OAP was shifted to the broader aspect of EAP. Since the 50s, the Occupational Social Work practice was already started developing dramatically (Gould \& Smith, 1980, cited by Sinha 
2007). Due to their multispectral intervention areas, EAP was started to be executed by Social Workers who could offer preventive, consultative and counseling services to the employees (Sinha, 2007). The activities of Social Workers in Industries under EAP were ranged from child care and medical referrals to marriage and family counseling, from workplace stress management to eldercare, from treatment of substance abuse to prevention of discriminations and sexual harassment in workplace (Kurzman \& Akabas 1993, cited by Sinha 2007).

EAP, the Present Scenario Worldwide: Employee Assistance Trade Association (2015) stated that, almost one fourth adults in the United States and Canada have symptoms of a mental health disorder, a substance use disorder, or both; and more than $75 \%$ of the people with these behavioral health disorders are employed in different sectors (Laird 2020). In Australia EAP service being offered are vocational assistance and old age support. The need for mental health support services has been felt by Chinese organizations for their employees. In France legislative recommendation has been made for entrusting 2,500 companies with more than 1,000 to make proposals to reduce stress and develop a prevention policy around psycho-social risks of the employees. Attrition in the call center industry in India has been found very high due to staff sleeping disorders, voice loss, hearing and eyesight problems. In Italy EAP is being practiced to deal with legal, financial, habitat and marital problems of the workers. The current trade of EAP in New Zealand is basically concerned with prevention of exploitation and sexual harassment of women in workplace. Saudi ARAMCO is the world's largest oil corporation (and largest Saudi employer) which has been providing EAP for decades. The Saudi national mental health program was developed in 1989 which is still running successfully by Saudi ARAMCO. Alcohol abuse is one of the most predominant problems of workers in Scotland which becomes crucial area of intervention in EAP. EAP in South Africa deals with the problems of HIV/AIDs and domestic violence in working community (Masi 2011). In a survey carried out by Vanson boume in December 2007 for Norwich Union Healthcare it has been discovered that alcohol is a major threat to employee's wellbeing and a factor encouraging sickness and absence.

Need for EAP; Situation Analysis in Indian Context : In a study in 2002 with 63 industry groups in India, 34 industry groups were recorded with higher absenteeism rate among which 18 industry groups were recorded with absenteeism rates of more than $10 \%$. In Public Sector, the highest rate of absenteeism was found in Manufacture of other electrical equipment sector i.e. $23.55 \%$. The causes of such absenteeism in Industrial workers are maladjustment with working condition, poor inhabiting conditions, industrial fatigue, and unhealthy working condition, absence of adequate welfare activities, alcoholism, indebtedness and family related responsibilities (Basariya 2012, p141). A study in different industries in Ward No 63, Govindapura Industrial area of Bhopal identified $38 \%$ industrial workers with allergic reactions resulting in to breathing problem and $38 \%$ workers with severe asthma. $36 \%$ of such workers were found with eye irritation, 31\% with skin diseases, $31 \%$ with frequent headache, more than $40 \%$ with muscular pain and general fatigue and 50\% with high blood pressure. The study concludes that unhygienic working environment of such industries is responsible for causing such health problems (Verma \& Singh 2015 p195). A study with IT Professionals in India confirms that $60 \%$ of the IT professionals' mental health is affected by their work stress. Especially the senior employees and women employees are highly affected due to stress in their work. It also affects their health and emotional balance (Subikshaa \& Jasmin 2018, p201). Another study on IT professionals of Indore reveals that IT professionals are severely suffering from high workload, poor working environment, poor relationship with their supervisors, peers and subordinates and unfriendly and hostile organizational climate (Joshi \& Modak 2018, p441). Working women in India frequently face the problems of sexual exploitation and harassments in workplace, gender biasness and discrimination regarding opportunities to growth and leadership and tough struggle to balance work and family life (Darji 2016, p60).

Social Work in EAP, the findings and conclusion: Employee Assistance Programs (EAP) has been 
developed out of the field of occupational social work (Green 2012). In macro level for overall workplace the EAP offers services including health and wellness programmes, reduction of workplace stress, crisis intervention programmes etc (Jacobson \& Lamb 2008) which are well accepted fields of intervention for social workers. Crisis intervention and strategic crisis management are the primary offers of EAP to the employer companies (Ottenstain \& Jacobson 2006). Social work's 7 stage model of Crisis intervention may be the most effective tool to deal with the issue. In addition to the direct assistance to employees in workplace, EAP provides services like work-life balance, child care, elder care, promotional health services, and informal literature services for the families of the employees. Some important problems of employees which EAP effectively handles are grief, parenting and interpersonal problems, stress, workplace conflicts and other psycho-social problems. Solution Focused therapy, system theory, ecological perspective, person in environment theory, problem solving approach can bring the best result to solve such problems (Jacobson \& Lamb 2008). It clearly indicates the significance of Social work intervention in EAP. The working women in India frequently face the problems of workplace discrimination, sexual harassments and severe family work conflicts (Darji 2016, p60). Feminist perspective of social work can ensure effective EAP to deal with such problems. EAP facilitates the programmes on prevention and therapeutic inputs to domestic violence, sexual harassment, anger management, substance abuse, stress management etc. where the EAP professionals apply all the social work methods, like case work, group work and community organization etc. (Mbuyisa 2019).

The author conducted a research on Social Work intervention in Human Resource Management, at Pandabeswar Coal Mines under ECL and Ambuja Cement Factory at Farakka in West Bengal in the year 2015. After analysis of the data, collected from the secondary sources such as Annual Reports and Sustainability Reports of the industries the author found that concerned policy of both the selected Industries emphasized on worker's personal and family well being, healthy lives, and development of interpersonal relationship in workplace. They aim into deal with their employees not in a manner of exploitation or violent usage like other mechanical resources, but in a way considering the workers as human beings with sense of rights and dignity, expectations, emotions, feelings, pain, joy and other human virtues and values. The selected industries incorporated the issues of ego-strengthening, personality development and development in problem solving abilities of the workers in their employee's assistance framework. The author found that both of the selected industries was emphasizing on assuring quality work life for their employees in terms of healthy work place environment, arrangement of health and safety measures in workplace and socio-cultural and healthy rejuvenating programmes for their employees as well. Comprehensive wellbeing and enhancing quality of life for both employees and their families were the highlights of their employees' assistance programmes. Empowerment of women workers and ensuring Gender Equality in work place were found to be the significant parts of the policies of the selected industries. The author found that both the industries, with their own initiatives, formed associations of women workers like Mahila Mandal, women forums etc. to ensure discrimination free working environment, protection of rights and prevention of sexual harassments of women workers in the working premises. Creating of discrimination, abuse and violence free working environment for all the employees were found to be the major areas of intervention under their policies for employees' support. After analyzing the contents of the responses from the Personnel/HR managers of both the selected workplaces the author identified 5 problems that frequently occurred to the workers and affected their careers. These problems were as follows:
* Family/Marital problems
* Alcoholism
* Indebtedness
* Gambling
* Problem of cope up with job environment during early days of work

From the responses of the Personnel /HR Managers the author identified 6 main tools, which were adopted 
frequently by the Personnel/HR Managers for solving such problems. These tools were:

* Individual counselling and family counseling

* Home visit of the workers for solving family and marital problems.

* Involving family members of the workers in recreational and social functions organized by the industry.

* Involving members of the work group in problem solving processes.

* Organizing anti addiction camps in the locality of the workers.

* Involving local woman SHGs/ CBOs/NGOs to prevent alcoholism and gambling.

More than 90\% Personnel/HR Managers responded that they used individual counselling and family counseling methods for employees' problem solving. 31\% stated that visit to the employees' home was proved to be an effective tool for them for solving family and marital problems of the employees. $54 \%$ of the respondents claimed that involving work group members in problem solving of the workers brought best result. $62 \%$ of the respondents claimed that organizing anti addiction camps brought satisfactory result in minimizing the rate of addicted employees. $38 \%$ respondents stated that involving local woman SHGs/ CBOs/NGOs to combat the problems of alcoholism and gambling contributed best to solve such problems.

Counselling is a very common problem solving tool used by professional social workers. Home visit is proved to be an effective tool of social case work. Involvement of work group to solve the problems of employees indicates the significant usage of tools and techniques of social group work. Organizing anti addiction camps and involving local woman SHGs/ CBOs/NGOs to combat the problems of alcoholism and gambling indicate the requirement of community organization method of social work in this regard. On the issue of motivational development $89 \%$ of the selected workers for the study responded that counseling from the part of their Personnel/HR Managers or immediate supervisors helped them best to develop their motivational level.
$48 \%$ of the workers responded that they experienced ego strengthening and personality development techniques from the part of their Personnel/HR Managers towards their motivational upliftment. $75 \%$ of the workers responded that their Personnel/HR Managers or immediate supervisors acted as effective mediators between them and the source of help they required for their motivational development. $75 \%$ of them also responded that their Personnel/HR Managers tried to identify their internal and external resources required to solve their problems. These responses indicate the importance of counseling and strength perspective of social work therapy for motivational development of the workers. It also stipulates the requirement of social work practitioners in industries as enabler, broker, negotiator, mediator etc. for solving employees' problem effectively.

EAP is getting inevitable in Industries day by day for organizational sustainability. EAP is completely person centric initiative. Effective EAP requires multispectral understanding of the service providers on psychosocial requirements of human beings and human rights as well as it requires the skills for shaping the external and internal fabrication of employees towards solving their problems and growth of their potentials. Social Workers posses the strong knowledge base on psychosocial and psycho dynamic inceptions of human beings. All the aforesaid evidences indicate that the methods of social work like social case work, social group work, and community organization have significant role to play in employee's assistance. Tools of social work like counseling, home visit etc, strength perspective, feminist perspective, crisis intervention model, solution focused brief therapy etc. do have significant usage to ensure effective EAP.

\section{REFERENCES}

Basariya, S.R. 2012. An empirical study on the stress management among bank employees in Madurai city, Madurai Kamraj University, Madurai, http://hdl.handle.net/10603/125574

Bedi, S.K. et al. 2018, Employee Assistance Programme: A Valuable Addition, ZENITH International Journal of Multidisciplinary Research, 8(8).

Darji, M. et al. 2016. The Challanges Faced by Indian Working Women to Balance Professional and Social Life in $21^{\text {st }}$ Century, Indian Journal of Technical Education, Special Issue for ICWSTCSC-2016, https://www.researchgate.net/publication/308747968 
Green, J. 2012. Employee Assistance Programs: Social Work at "Work", Practice Perspectives, Issue Fall, October 2012, The National Association of Social Workers, Washington DC, USA.

Jacobson, J.M. and Lamb, J.H. 2008. Working it Out - Social Work in Employee Assistance, March/April 2008, https://www. researchgate.net/publication/268334097

Joshi, N. and Modak, K.C. 2018. A Study on Stress Management in IT Sector with Special Reference to Indore, Journal of Emerging Technologies and Innovative Research, 5(8).

Laird, M. 2020. Employee Assistance Programs - Social Work's Influence, Social Work Today, Spring City, USA, https://www. socialworktoday.com/news/pp_102617_1.shtml, 2020,

Lal, K. 2005. 'Human Resource Management, An Indian Perspective', Abhijeet Publication, Delhi.

Masi, D.A. 2011. Definition and History of Employee Assistance Programs, University of Maryland, Baltimore, http://hdl.handle. net/10713/3360

Mbuyisa, K.H. 2019. A Comparative Study Between Employee Assistance Programme and Occupational Social Works in the Gauteng Province, South Africa, Faculty of Humanities Department of Social Work and Criminology at the University of Pretoria, Pretoria, South Africa.
Mishra, B. and Kar, N. 2003. Managing Work Related Problems in Industries- The Need for Employee Assistance Programmes, Indian Journal of Occupational and Environmental Medicine, 7(1).

Rathnamma, R. and Prasad, T.R. 2017. Industrial Disputes in IndiaAn Analysis, Shanlax International Journal of Economics, 5(3).

Sarkar, S. 2008. Industrial Social Work to Corporate Social Responsibility: A Transformation of Priority, Journal of Human Values, April 2008, DOI: 10.1177/097168580701400105.

Sharma, A.K. and Mishra, D. 2017. HRM Practices in Social Work, Himalayan Publishing House, Bengaluru.

Sinha, D. 2007. Aspects of Industry and Occupational Social Work, Abhijeet Publications, Delhi.

Subikshaa, P. and Jasmin, K.S.S. 2018. Stress Faced by Employees in Information Technology Sector in India, International Journal of Pure and Applied Mathematics, 119(17): 201-206.

Verma, N. and Singh, M.M. 2015. Health Related Problems in Industrial Workers due Environmental Hazards, International Journal of Science, Technology and Management, 4(7).

Zastrow, C.H. 2010. Evaluating Social Work Practice, Learning India Private Limited, New Delhi. 